\title{
TAP into the Library
}

\author{
by Kem Ellis
}

\section{U}

se technology, not branch libraries, to improve access and convenience for library users!" This is the message High Point Public Library's board of trustees heard loud and clear in the summer of 1998 during a series of six community focus groups. This article describes the library's collaborative plan to fulfill this mandate from High Point's library users and to design a new approach to providing multiple library access points in an urban setting.

Rather than building branches to serve the many neighborhoods of High Point, the High Point Public Library (HPPL), using a Library Services and Technology Act (LSTA) grant, launched its TAP into the Library project in March 2003 to enable children in the inner-city neighborhood of Southside to tap into their public library by accessing the library's Internet catalog to select library materials and place holds on them. HPPL's first TAP, an acronym for Technology Access Point, was established at the Family Resource Center (FRC) located in the Southside Recreation Center. The FRC is a collaborative project of Family Service of the Piedmont and the United Way of Greater High Point's Success by Six program.

\section{Collaborative Partners in the TAP Project}

The collaborative partners for the TAP project are the HPPL, which serves as the lead partner, Family Service of the Piedmont, Fairview Elementary School, and United Way of Greater High Point. Among North Carolina's eight municipal public library systems, the HPPL is the largest, occupying a 67,000-square-foot facility opened in the city's central business district in 1992. The HPPL is a community leader in providing programs, services, and materials for children and teens that nurture reading and learning. Although there are no traditional branch libraries, the library operates a mobile library that visits daycare homes, owns some 300,000 items, and has a \$3.8 million annual operating budget. The library uses Horizon as its automated system and has its own Web site and Internet catalog, HIP, an acronym for Horizon Internet Portal. The library has a staff of seventy-two full- and part-time employees. The library director and the head of Extension Services serve as the library's representatives in the TAP partnership.

The FRC, staffed by Family Service of the Piedmont, received a grant in October 1998 from United Way of Greater High Point's Success by Six initiative to serve as an umbrella organization to provide programs for children and families in the Fairview Elementary School district. The FRC provides neighborhood-based programs that are prevention-focused and familycentered. Families are encouraged to use existing skills and develop new skills and resources to support healthy family functioning and positive child 
development outcomes.

Fairview Elementary School, with 598 students in grades K-5, has a history of low academic achievement. As recently as 1997 the school was at risk of being ranked as a low performing school based on poor results on endof-grade testing. During the past five years, however, Fairview has seen dramatic improvement in its academic standing because of its

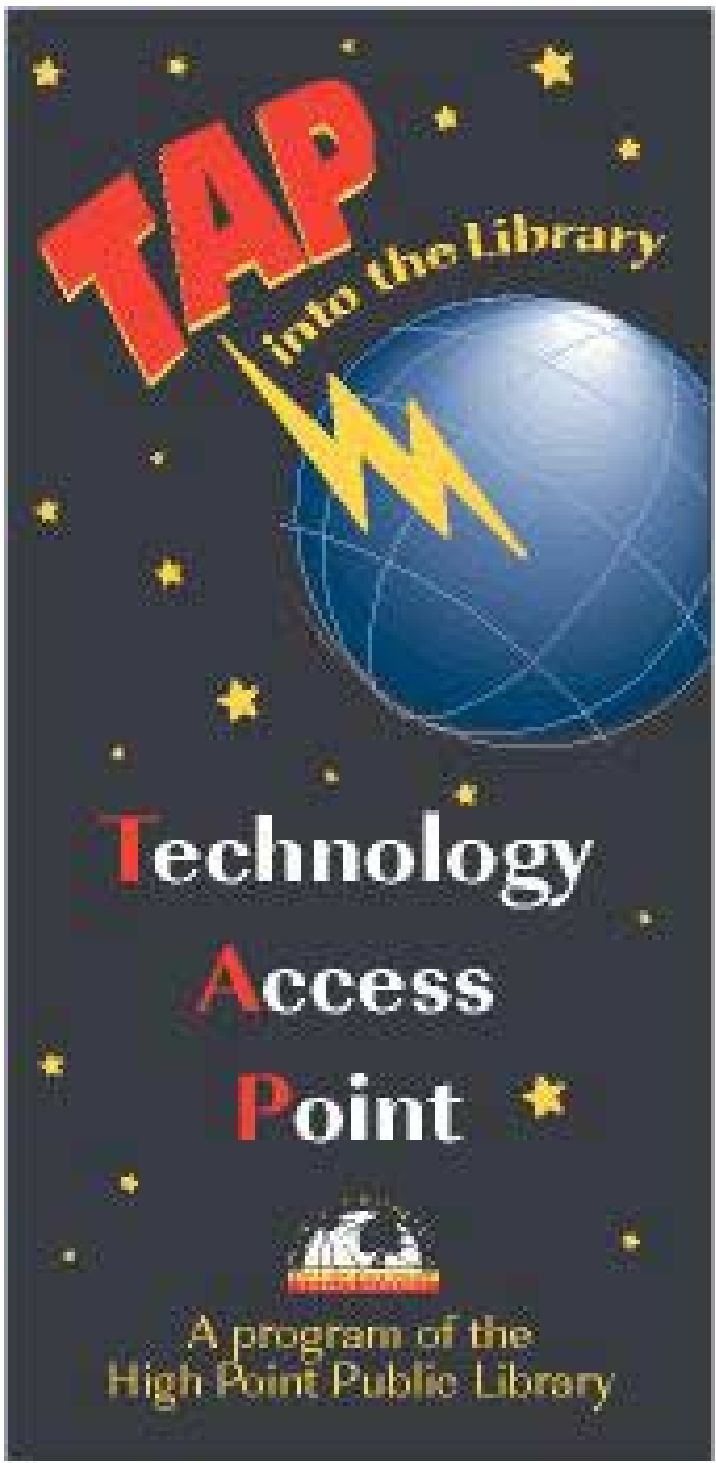
participation in the Bridges to Success program. Now Fairview is recognized as an asset in this neighborhood due to its strong principal and dedicated staff. Although parental involvement is consistently very low, substantial improvement has been seen since the United Way began working with the school, parents, and the neighborhood. Due to the social and economic pressures faced by Fairview students and their families, finding new ways to building on their recent successes is a constant challenge. ${ }^{1}$

United Way of Greater High Point is a collaborative partner through its division of Children's Initiatives, which provides the Success by Six and Bridges to Success programs. The mission of the Bridges to Success program is to turn public schools into community centers, open during non-school hours to provide after-school programs, on-site tutoring, adult education, parent workshops, and cultural programs. The academic curriculum of Fairview is fully integrated with the after-school and evening programs. Some parents that were thinking of leaving Fairview now want to remain in the community because of the Bridges to Success program.

The High Point Public Library has a long history of collaboration with United Way of Greater High Point. The library director sits on the executive committee of United Way's board of directors, and chairs the Community Investment Committee. Other library staff members serve on the United Way executive board on its Children's Initiatives board that oversees the Success by Six program. In 2000, the Success by Six program donated $\$ 45,000$ toward the purchase of the HPPL's mobile library.

\section{The Community Need}

Since the HPPL does not operate branch libraries, it is challenged to provide adequate access to the library for all residents of the community, some of whom are unable, for various reasons, to use the main library. By 1998, it was clear that a city the size of High Point should be providing library services from more than one facility. The trustees commissioned a study to obtain citizen input for their long-range plan for improving access to the library. The trustees wanted to know whether or not library users in High Point wanted traditional branch libraries. ${ }^{2}$ The library staff assumed that there would be a loud outcry for a branch from north High Point residents, where residential growth was booming and library use was heavy. What the library staff heard was surprising.

The first focus group in the series was conducted in north High Point. These focus group participants, many of whom were regular library users, challenged us not to build traditional branch libraries. Citizens of north High Point said that unless we intended to duplicate the main library in their neighborhood they would still need to come to the main library regularly in order to find everything they needed. "What we really want is a place where we can use the Internet, search the main library catalog, and reserve materials and have them delivered to us," was their collective response. These forward- 
thinking library users went on to tell us that they thought it would be a mistake to dilute the vast resources of the main library by trying to maintain branch libraries that in their opinion would always be inferior to the main library.

What an eye-opener this was! Library users were thinking outside the box, and challenging the library staff to do the same. As this idea began to take shape, the library staff began to weave a new concept into subsequent

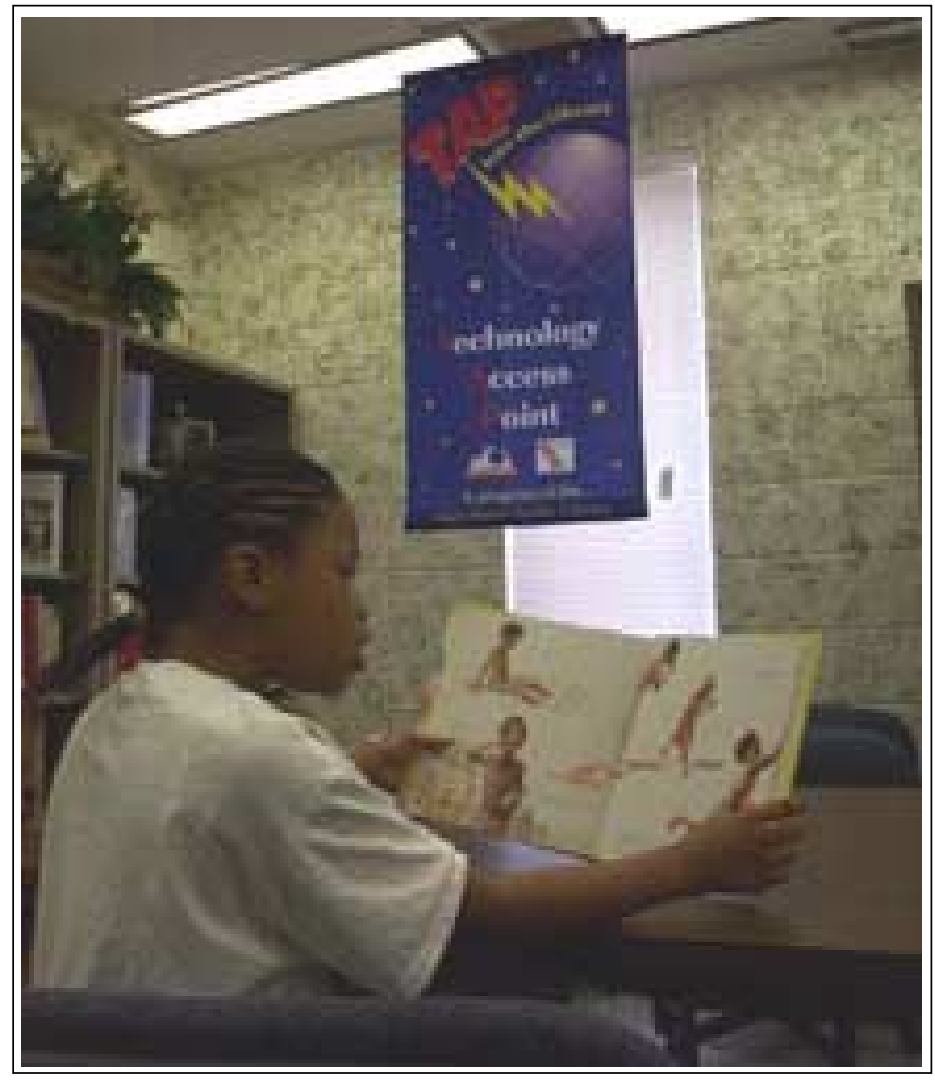
focus group sessions. The concept of using technology rather than traditional library branches to extend library services to the community was enthusiastically endorsed throughout the city.

Access is not an issue for people with their own transportation, and for children who have older people in their lives to bring them to the library regularly. Many of our inner-city residents do not have readily available transportation, and a majority of our inner-city children and youth do not have an adult or older person who can or will bring them to the public library. Many of the students attending Fairview Elementary School live in singleparent families, sometimes under the custodial care of a grandparent or aunt. Fairview also serves children who reside at the Salvation Army shelter in temporary housing provided for mothers and their children. These living arrangements may last from a few weeks to several months. Consequently the school population is in constant flux as families move in search of affordable housing, decent jobs, and acceptable living conditions.

The population this project serves consists of children and teens living in families characterized by high incidents of crime, substance abuse, and limited income. Many children living in the Southside neighborhood go home each day to families stressed by unstable or inadequate housing, unstable income, a history of substance abuse, young and immature parents with less than a high school education, female-headed single-parent households, three or more children in the family, social isolation, and unrealistic child development expectations. These children and teens live in a socially isolated neighborhood and have little or no access to the public library. According to the National Adult Literacy Survey, twenty-five percent of adults in High Point score at level 1 proficiency and twenty-nine percent score at level 2 proficiency. ${ }^{3}$ While literacy findings at the neighborhood level are not available, these percentages are most likely higher in the Southside neighborhood.

The TAP into the Library project increases the rate at which Southside children and teens use the public library by locating a smaller facility in their own neighborhood. This project provides children and teens in one highly impacted inner city neighborhood with virtual and physical access to the full resources and expertise of the public library right in their own neighborhood, and in their own homes.

\section{How the TAP into the Library Program Works}

The basic function of the TAP into the Library project is to serve as a virtual, rather than physical, public library branch to allow children who attend Fairview Elementary School, teens who attend the Boys and Girls Club housed in the same recreation center facility, and their families who visit the 
center, to use the Internet to access the library's online catalog to locate materials from the library's collections. They can use their smart cards issued by the library to place holds on the items they select as they search the catalog.

Library staff couriers take the materials to the FRC each day, and volunteers on duty at the FRC check them out to the borrowers who requested them. Volunteers at the FRC received training for operating the TAP virtual branch from library professionals at the High Point Public Library. Michelle McNair, director of the FRC, supervises the day-to-day operations of the virtual branch and also recruits the volunteers. Students at Fairview Elementary School are trained to use the online library catalog in their school media center by Mary Nifong, the school's media specialist. The media center staff is also helping the library select materials for the branch. Displays of relevant materials as well as library programs are also developed for Fairview's TAP to meet specific neighborhood needs and objectives.

The TAP into the Library project improves library service to Southside residents by providing a location in their own neighborhood where they can go to select and place holds on library materials on-line. The user can select the TAP as the location where their holds will be delivered. The user will have the option of using the requested items at the TAP, or checking them out. A small circulating collection of new and relevant print items is also available on-site. The library staff and the volunteers in the FRC, who work with these students each day, need some relevant and useful materials that the students can check out with their own TAP into the Library cards. A small circulating collection of new books, available at the FRC, replaced a small, donated collection of second-hand books that was unfocused, and woefully inadequate to meet the needs of the children who use the FRC. As

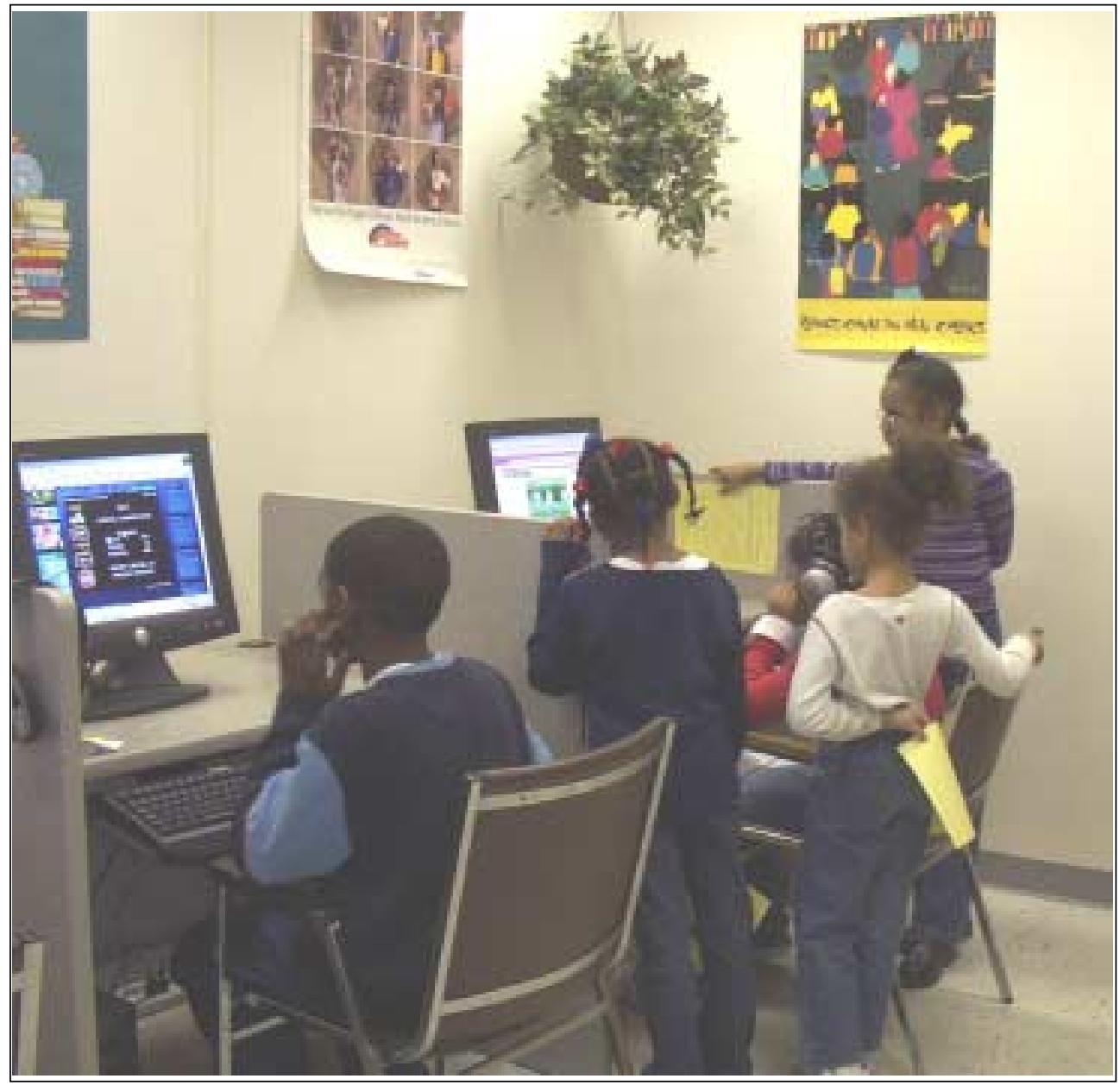
the children, teens, and families in the Southside neighborhood experience success in using the small onsite collection, they are more likely to value what it means to have access to the wealth of information and resources housed in the main library. This small collection housed in the FRC is meant to prime the pump as children and teens in the Southside neighborhood form library habits that will last a lifetime. Adequate shelf space has been planned in order for this collection to grow as the project continues beyond the first year.

\section{Virtual reference}

In addition to the traditional library services - getting a library card, using the Internet, and checking out books - the virtual branch at the Fairview FRC offers a virtual connection to the reference staff at the main library. Users of the 
service receive virtual reference assistance in real time. The library has contracted with OCLC to use their QuestionPoint virtual reference software, and with Convey Systems to add the enhanced connectivity of voice and video between the FRC and the reference desk at the main library. The library selected Convey's OnDemand interactive system in order to provide real-time interactive reference service over the Internet. ${ }^{4}$ This service is integral to achieving the goal of making the library a visible and integral part of the Southside neighborhood. The OnDemand system allows the children and teens, who participate in the TAP into the Library project, to receive face-toface reference service from professional reference staff at the main library.

At the main library, reference librarians can see and talk to students using Logitech Web cams located in the main library and in the virtual branch. Besides real-time communication, the software has two main functions. The librarian can control the user's Web browser and mouse to help with Internet research, and, also, the application-sharing feature makes it possible for the librarian to type directly into a user's document.

\section{Cost of the Project, Impact, and Future Opportunities}

The HPPL provided computers, furniture, materials, and library cards for the Fairview TAP using $\$ 36,508$ in federal LSTA funds through a Powerful Partners collaboration grant administered by the State Library of North Carolina. ${ }^{5}$ The Success by Six program of United Way of Greater High Point provided the ten-percent matching funds of $\$ 3,650$, for a total cost of slightly more than $\$ 40,000$.

The virtual library is intended to increase the public library's visibility in the community and, ultimately, to make children and teens and their parents more familiar with the library and more comfortable using it. The computer lab looks like any other at first glance, except for the Web cams placed inconspicuously at each computer workstation. When older students need help with their homework, the reference librarian at the main library is only a few clicks away. FRC director Michelle McNair reports that several parents have been warming up to the computers, and that now most students and parents at Fairview Elementary school own a library card. In May 2003, the virtual branch logged more than 300 sessions from kids wanting to tap into the library.

Other TAP projects for other High Point neighborhoods are being planned. The City of High Point budgeted the funds needed to locate a second TAP into the Library virtual branch in the new Macedonia Community Center, which opened in another inner-city neighborhood in August 2003.

\section{References}

${ }^{1}$ City of High Point, Department of Planning and Development, Census 2000: A Comprehensive Profile and Analysis of Demographic and Socioeconomic Information Report in the 2000 Census (2000), 17.

2 City of High Point, Land Use Plan for the High Point Planning Area (Apr. 6, 2000), 5.

${ }^{3}$ Irwin S. Kirsch, Ann Jungeblut, Lynn Jenkins, and Andrew Kolstad, Adult Literacy in America: A First Look at the Findings of the National Adult Literacy Survey (National Center for Education Statistics, 1993).

${ }^{4}$ Convey Systems OnDemand Product Overview, available at http:// www.conveysystems.com/overview.asp (Accessed Sept. 29, 2003.)

${ }^{5}$ State Library of North Carolina, Powerful Partners Collaboration Grants, available at http://statelibrary.dcr.state.nc.us/lsta/PP GL 03-04.pdf (Accessed Sept. 29, 2003.) 